\title{
The role of atopy in otitis media with effusion among primary school children: audiological investigation
}

\author{
F. Martines - G. Martinciglio - E. Martines • \\ D. Bentivegna
}

Received: 10 February 2010/ Accepted: 25 May 2010/Published online: 9 June 2010

(C) Springer-Verlag 2010

\begin{abstract}
The objective of this study was to evaluate the role of atopy in otitis media with effusion (OME) in children attending primary school in western Sicily focusing on the audiological characteristics among atopic and nonatopic subjects suffering from OME. A total of 310 children (5-6 years old) were screened by skin tests and divided into atopics (G1) and non-atopics (G2). The samples were evaluated for OME by pneumatic otoscopy, tympanogram and acoustic reflex tests. The parameters considered were: documented persistent middle ear effusion by otoscopic examination for a minimum of 3 months; presence of B or C tympanogram; absence of ipsilateral acoustic reflex and a conductive hearing loss greater than $25 \mathrm{~dB}$ at any one of the frequencies from $250 \mathrm{~Hz}$ through $4 \mathrm{kHz}$. A total of 56 children $(18.06 \%)$ resulted to be atopics while 254 were non-atopics. OME was identified in
\end{abstract}

F. Martines

Sezione di Otorinolaringoiatria, Dipartimento di Neuroscienze

Cliniche (DINeC), Università degli Studi di Palermo,

Via del Vespro, 129, 90127 Palermo, Italy

G. Martinciglio - E. Martines - D. Bentivegna

Sezione di Audiologia, Dipartimento di Biotecnologie Mediche e

Medicina Legale (DIBiMed), Università degli Studi di Palermo,

Via del Vespro, 129, 90127 Palermo, Italy

e-mail: gioacchino65@interfree.it

E. Martines

e-mail: martines@unipa.it

D. Bentivegna

e-mail: bentivegnad@gmail.com

F. Martines ( $\square)$

Via Autonomia Siciliana 70, 90143 Palermo, Italy

e-mail: francescomartines@unipa.it
24 atopic children and in 16 non-atopic children for a total number of 40 children; the overall prevalence rate was $12.9 \%$ ( $42.85 \%$ for $\mathrm{G} 1$ and $6.30 \%$ for G2). OME was bilateral in 28 children (70\%), with a significative difference between G1 $(79.17 \%)$ and G2 $(56.25 \%)$. The prevalence of B tympanogram was $70.59 \%$, corresponding to $79.07 \%$ for G1 and $56 \%$ for G2. The mean air conduction pure tone was, respectively, $31.97 \mathrm{~dB}$ for $\mathrm{G} 1$ and $29.8 \mathrm{~dB}$ for G2. The prevalence value of OME in atopic children, also supported by the higher predominance of bilaterality, B tympanogram and hearing loss among this group, could suggest the important role of allergy in the pathogenesis of OME.

Keywords OME - Otitis media with effusion . Allergy $\cdot$ Eustachian tube dysfunction

\section{Introduction}

Otitis media with effusion (OME) describes an inflammatory process within the middle ear space that is generally associated with the accumulation of fluid. Persistent middle ear fluid from OME results in decreased mobility of the tympanic membrane and serves as a barrier to sound conduction. It is a common disease in children with an incidence range from 6 to $64 \%$, depending on the methods used and population characteristics, and which may lead to hearing loss, learning difficulties and delay of language development [1-6]. Approximately, 90\% of children (80\% of individual ears) have OME sometimes before school age, most often from 6 months to 4 years of age. In the first year of life, $>50 \%$ of children experience OME, increasing to $>60 \%$ by 2 years. Many episodes resolve spontaneously within 3 months, but $\sim 30$ to $40 \%$ of children have 
recurrent $\mathrm{OME}$, and $5-10 \%$ of episodes last 1 year or longer [7-9]. The pathogenesis of OME is clearly related to the dysfunction of the eustachian tube [10]. Upper respiratory tracts infections (URTI) are one of the most common causes of eustachian tube dysfunction and thus OME among children 1 year old or younger than among 2- or 3 -year-old children. Mechanical obstruction of the nasopharyngeal opening of the eustachian tube by adenoid hypertrophy or craniofacial malformations, such as cleft palate deformities and Down syndrome, also cause OME in younger children [11]. The involvement of IgE-mediated allergic reactions in the pathogenesis of OME has been suggested by clinical observations of a high prevalence of OME among patients with allergies [12-14]. In fact, several studies evidenced that $40-50 \%$ of children with OME, older than 3 years, had nasal allergy, whereas $21 \%$ of allergic children had OME. Other studies showed no association with allergic disease during the first 3 years of life, suggesting that allergy did not play a dominant role in OME at a younger age [11]. It is known that middle ear mucosa itself is rarely a target organ for allergy and the release of biologic mediators of inflammation from basophils and mast cells occurs in the nasal and nasopharyngeal mucosa. These mediators most likely produce eustachian tube edema and inflammation. Over a long period this chronic inflammatory response, along with viral or bacterial infection, produces middle ear effusion [15]. A recent clinical practice discussion and literature review states that "the relation between allergy and OME will remain controversial until well-controlled clinical studies are conducted documenting that in select populations anti-allergy therapy is efficacious in preventing or limiting the duration of OME" [16].

Although in the last few years, there has been a great consensus among the studies with respect to the role of atopy in OME, the knowledge of the audiological characteristics of OME among atopic and non-atopic subjects is yet incomplete.

The aim of this study, carried out on primary school children aged 5-6 years who underwent skin prick tests, was to evaluate the prevalence of OME among the screened population to determine any difference either in OME incidence or in audiological characteristics between atopic and non-atopic subjects suffering from OME.

\section{Materials and methods}

This study was carried out by the Department of Audiology, University of Palermo, together with the District of Sciacca, examining a group of children attending primary schools in Sciacca from September 2006 to June 2007. The subject group consisted of 313 patients, 155 males and 158 females, ranging from 5 to 6 years of age. The study protocol was fully explained to patients or their guardians, and written informed consent was obtained from each patient. Children with skull-facial malformations, Down syndrome, perforated drums and ventilation tubes were excluded from the study. At the time of the first screen, all the children underwent skin prick tests and otoscopic examination. Skin tests were performed using 12 common perennial and seasonal allergens: Alternaria, Aspergillus, Cladosporium, Penicillium, ragweed, grass mix, trees mix, cockroach, dust mites, Dermatophagoides farinae, Dermatophagoides pteronyssinus and cat and dog epithelium. The food allergens tested were: dairy, egg, peanut, tree nut, seafood, shellfish, soy and wheat. Solutions of histamine and saline were used as positive and negative controls, respectively. The results were evaluated after $10 \mathrm{~min}$. Wheals $\geq 3 \mathrm{~mm}$ in diameter than wheals at the site of the negative control were considered positive. Children with at least one positive skin prick test to any antigen were classified as atopic and included in group 1 (G1), while children with negative skin prick test served as non-atopic controls and were included in group 2 (G2). Patients in both groups were evaluated for OME and underwent pneumatic otoscopy. When abnormalities suggestive of OME, which included presence of retracted tympanic membranes, fluid level, bubbles or hypervascularity, were noted, tympanogram and ipsilateral acoustic reflex were performed. The instrument used was a tympanometry machine, model Amplaid 766, with a probe frequency of $220 \mathrm{~Hz}$ and an air pressure range of -400 to $100 \mathrm{mmH}_{2} \mathrm{O}$ with automatic recording. Tympanograms were divided into the following types: type $\mathrm{A}\left(+99\right.$ to $\left.-99 \mathrm{mmH}_{2} \mathrm{O}\right)$, type $\mathrm{C} 1$ $\left(-100\right.$ to $\left.-199 \mathrm{mmH}_{2} \mathrm{O}\right)$, type $\mathrm{C} 2\left(>-200 \mathrm{mmH}_{2} \mathrm{O}\right)$ and type $\mathrm{B}$ (flat curve without peak identification). For ipsilateral acoustic reflex, the same machine was used: an Amplaid 766, with a signal of $105 \mathrm{~dB}$ HTL and pure tone stimulus at 1,000 and 2,000 Hz. Children with otoscopic appearance of OME and abnormal tympanogram (type B or $\mathrm{C}$ with no stapedial reflex) were regarded as positive screens and given a follow-up appointment within 3 months after the initial screening. The criteria for diagnosis of OME in the study were as follows: documented persistent middle ear effusion by otoscopic examination for a minimum of 3 months; presence of $\mathrm{B}$ or $\mathrm{C}$ tympanograms; absence of ipsilateral acoustic reflex and a conductive hearing loss greater than $25 \mathrm{~dB}$ at any one of the frequencies from $250 \mathrm{~Hz}$ through $4 \mathrm{kHz}$. Audiogram was performed if the child had a type B or C tympanogram. Audiometric tests were performed using a duly calibrated pure tone audiometer and were applied to each ear at frequencies of $0.5,1.0,2.0$ and $4.0 \mathrm{kHz}$.

Statistical analysis were performed using the Matlab ${ }^{\circledR}$ computer program. 


\section{Results}

The total number of children examined was 313 , but 3 children were excluded from the study because of skullfacial malformations and perforated drums. A total of 310 children were analyzed. The age of children ranged from 5 to 6 years, with a mean age of 5.56 years (5.59 for male and 5.53 for female). Of the children, 155 (50\%) were boys and 155 girls.

At the time of the first examination, based on skin tests, children were classified into two groups: G1 (atopics) including 56 children $(18.06 \%)$ with positive skin tests and G2 (non-atopics) including 254 controls (81.94\%) with negative skin tests.

Of the 56 children belong to G1, 29 patients (51.78\%) had positive skin tests for both inhalant and food allergens; 17 patients $(30.36 \%)$ had a positive test only for food allergy; $10(17.86 \%)$ patients had an allergy only against inhalant allergens.

During pneumatic otoscopy, a total of 44 children were found with suspected OME. Of these, four were found without any evidence of OME in the follow-up appointment after 3 months and were excluded from the study. A total of 40 children (overall prevalence rate of $12.9 \%$ ) who suffered from persistent OME were studied ( $\geq 3$ months), of which 12 were boys and 28 were girls.

Of the 40 children with OME, $24(60 \%)$ were atopic (G1), while 16 (40\%) were non-atopic (G2) (Fig. 1a, b).

Of the 56 children belonging to G1, 24 (42.85\%) were found to suffer from OME while $32(57.15 \%)$ were healthy. Of the 254 non-atopic children belonging to G2, 16 $(6.29 \%)$ were diagnosed with OME while the others $(93.71 \%)$ were healthy (Table 1) (Fig. 2).

Of those suffering from OME, 12 were boys ( $7 \mathrm{G} 1$ and 5 G2) and 28 were girls ( $17 \mathrm{G} 1$ and $11 \mathrm{G} 2$ ). The rate of OME was $30 \%$ for boys (29.16\% for G1 and $31.25 \%$ for $\mathrm{G} 2$ ) and $70 \%$ for girls $(70.83 \%$ for $\mathrm{G} 1$ and $68.75 \%$ for $\mathrm{G} 2$ ).

A total of 28 subjects had bilateral OME (70\%) and 12 had unilateral OME (7 right ear and 5 left ear) for a total of 68 ears. In G1, OME was found as bilateral in 19 cases
Table 1 Distribution of 310 children according to atopy and OME

\begin{tabular}{|c|c|c|c|c|c|}
\hline \multirow[t]{3}{*}{ Groups } & \multicolumn{4}{|c|}{ Otitis media with effusion } & \multirow{3}{*}{$\begin{array}{l}\text { Total } \\
N\end{array}$} \\
\hline & \multicolumn{2}{|c|}{ Yes } & \multicolumn{2}{|l|}{ No } & \\
\hline & $N$ & $\%$ & $N$ & $\%$ & \\
\hline G1 & 24 & 42.85 & 32 & 57.15 & 56 \\
\hline \multirow[t]{2}{*}{ G2 } & 16 & 6.30 & 238 & 93.7 & 254 \\
\hline & 40 & 12.9 & 270 & 87.1 & 310 \\
\hline
\end{tabular}

$\chi^{2}=54.56, d f=1, P=1.50^{-13}, \mathrm{OR}=11.16$

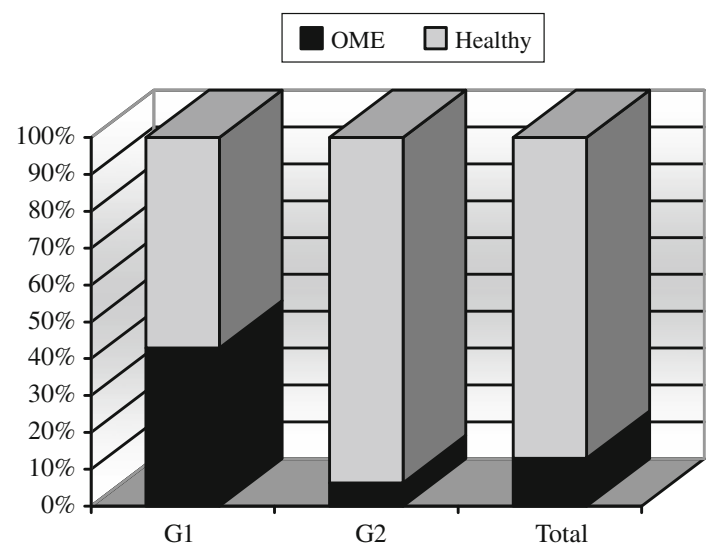

Fig. 2 Percentage values of OME in the population

(79.17\%) and unilateral in 5 cases $(20.83 \%)$ for a total of 43 ears, while in G2, OME was found as bilateral in 9 cases $(56.25 \%)$ and unilateral in 7 cases $(43.75 \%)$ for a total of 25 ears (Fig. 3a, b).

Of the total of 68 ears, 48 ears $(65 \%)$ had B tympanogram with negative reflex test and 20 had $\mathrm{C}$ tympanogram with negative reflex test $(35 \%)$. As for atopic children with OME (G1), 34 ears (79.07\%) had B tympanogram and 9 had $\mathrm{C}$ tympanogram (20.93\%), while in $\mathrm{G} 2$, 14 ears (56\%) had B tympanogram and 11 had C tympanogram (44\%) (Fig. 3c, d).

Regarding the audiometric threshold observed in the OME population, 42 ears $(61.76 \%)$ had a hearing loss between 25 and $30 \mathrm{~dB} ; 22(32.35 \%)$ between 35 and
Fig. 1 Distribution of pediatric population according to $\mathrm{OME}$ and atopy; a absolute values; b relative values
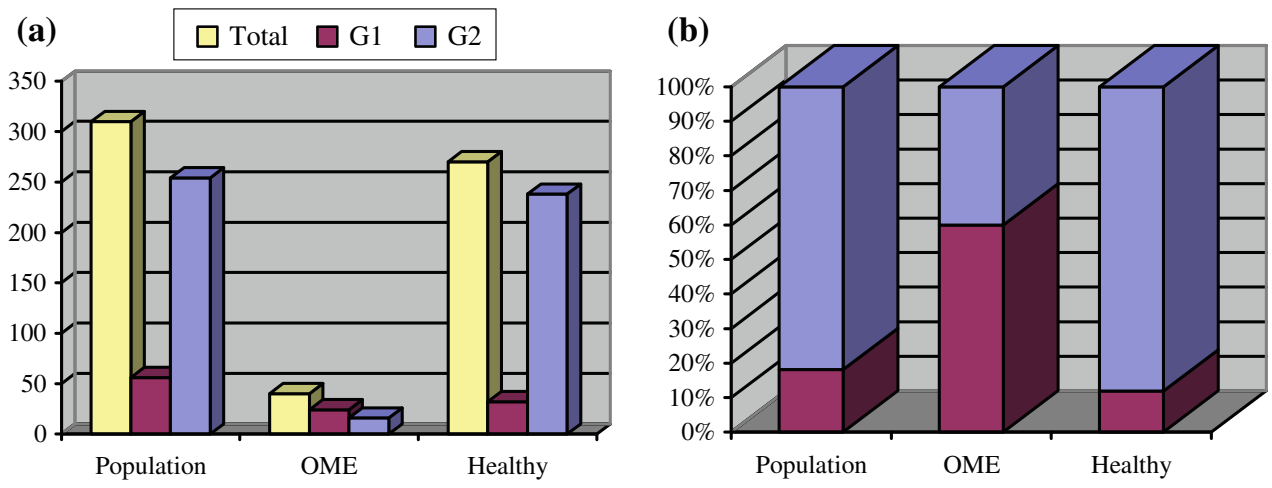
Fig. 3 Audiological characteristics of the OME population
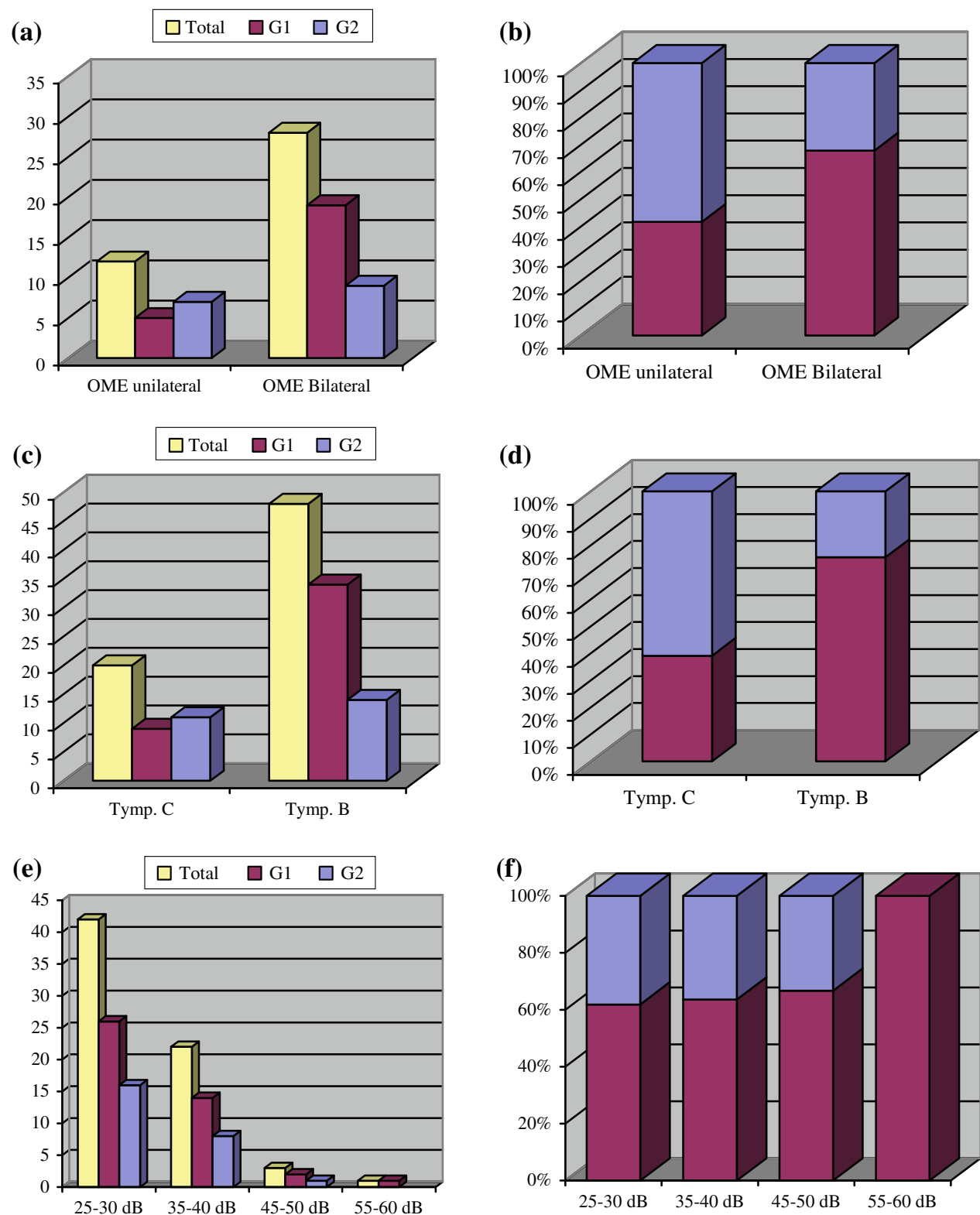

(d)

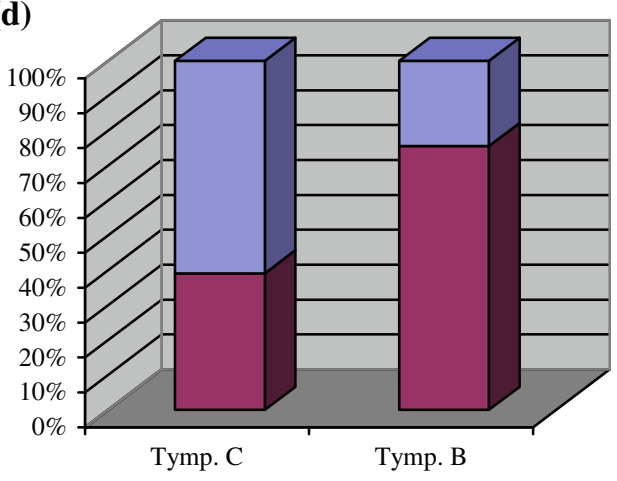

(f)

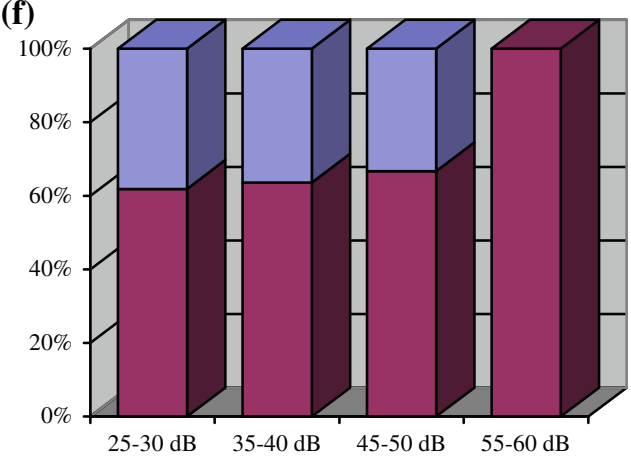

$40 \mathrm{~dB} ; 3(4.41 \%)$ between 45 and $50 \mathrm{~dB} ; 1$ (1.47\%) between 55 and $60 \mathrm{~dB}$. The mean air conduction pure tone according to diagnosis at frequencies $500 \mathrm{~Hz}-4 \mathrm{kHz}$ was, respectively, $31.97 \mathrm{~dB}$ for $\mathrm{G} 1$ and $29.8 \mathrm{~dB}$ for $\mathrm{G} 2$ (Fig. 3e, f).

\section{Discussion}

OME is defined as the presence of fluid in the middle ear without signs or symptoms of acute ear infection. It is a common disease in children, which may lead to hearing loss or surgical intervention. In most children, OME improves spontaneously and has a good prognosis, but approximately $10 \%$ of pediatric patients experience repeated or chronic OME. In addition to hearing loss, chronic OME may be associated with learning difficulties and delay of language development.

The reported prevalence rates of OME among primary school children in literature were as follows: $10.4 \%$ in a study from Turkey including 912 children between 6 and 8 years of age [17]; $6.8 \%$ in Italy $(2,132$ children, $5-14$ years old) [18] $9.5 \%$ in the Netherlands (1,004 children, 5-8 years old) [19]; $13.8 \%$ in Saudi Arabia (4,124 children, $1-8$ years old) [20]; $6.5 \%$ in Greece $(5,121$ children, 6-12 years old) [21].

The prevalence rate of OME in our study including 310 children between 5 and 6 years of age is $12.9 \%$. Our results are higher than those in most other studies. Many factors may explain the differences between these prevalence 
rates. Irrespective of the researcher's method, age is one of the most important risk factors for the disease. On reviewing some articles about the issue, Zielhuis et al. [22] used an age-specific prevalence rate and came to the conclusion that the rate has two peaks: one around 2 years of age, probably leading both to immaturity of function of the immune system and to anatomical and functional diversity of the eustachian tube (i.e., nearly horizontal orientation), and the other around the age of 5 years, probably leading to a higher percentage of URTI among children attending the same class. Our population presents an age range of 5-6 years that coincides with the second peak reported by Zielhuis, confirming the important role of age as risk factor for OME. In fact, our prevalence was lower than that reported in the study conducted in Saudi Arabia (13.8\%) in which the age range was 1-8 years that includes both the peaks reported by Zielhuis. As for sex, some previous studies found that OME was encountered more frequently in boys than in girls, whereas others found no sex-related differences. In our study, the number of girls with OME significantly exceeded the number of boys $\left(\chi^{2}=7.384\right.$; $P=0.0067)$.

Besides the methods used and the age considered, the different prevalence rates may also depend on the high percentage of atopy among the population screened. In fact, controlled studies have shown an increase in the prevalence of OME in children with an atopic history or positive skin prick tests compared with normal children [23]. Atopy has been defined as the sensitization or predisposition to hyperreactivity to a normal non-reactive antigen. Allergic patients are considered to be those who express symptoms related to exposure and are not merely sensitized. Approximately, 20-30\% of the general population and $10-15 \%$ of children are atopic [24]. In our study, to value the role of atopy, all the pediatric population was screened by means of routine skin testing; of 301 subjects ranging from 5 to 6 years of age, atopy was evidenced in $18.06 \%$ (56 subjects) (Fig. 1b). Allergy may be related to OME etiology through different mechanisms. Experiments indicated that the middle ear mucosa was capable of sustaining an allergic reaction; however, the extent and duration of inflammation were limited, and OME was not observed. Given that the middle ear space is an anatomical extension of the airway by way of the eustachian tube, the middle ear may be considered a component of the united airway in atopic individuals. The allergic inflammation is not isolated to the middle ear, but occurs uniformly in the nasopharynx, middle ear and eustachian tube, leading to the development of OME [25].

Our epidemiologic data seem to support the existence of a relationship between OME and atopic disease. In fact, of 310 children ranging in age from 5 to 6 years old, OME was diagnosed in a total of 40 children (overall prevalence rate $12.9 \%)$. Of these, $60 \%$ were atopic ( 24 children), while $40 \%$ (16 children) were non-atopic. Of a total of 56 atopic children, $24(42.85 \%)$ were found to suffer from OME, while 16 of 254 non-atopic children $(6.29 \%)$ were diagnosed with OME (Figs. 1b, 2). Other investigators, using objective intradermal and in vitro testing, have demonstrated that $72-100 \%$ of the children with OME are atopic: Tomonaga (72\%) [26], Nsouli (78\%) [27], Hurst (81\%) [28], McMahan (93\%) [29], Hall (100\%) [30]. Statistical analysis evidenced a significant correlation between atopy and OME with a correlation index of $r=0.998$ $\left(\chi^{2}=54.56 ; P=1.50^{-13} ;\right.$ OR $\left.=11.16\right)$.

The role of atopy in the development and persistence of OME may be supported by the different audiological characteristics between atopic and non-atopic subjects suffering from OME. In our study, we found a predominance of bilateral OME in atopic subjects with respect to non-atopics. In fact, of a total of 40 children suffering from OME, 28 subjects had bilateral OME and of these $67.86 \%$ were atopic (19 children corresponding to $79.17 \%$ of the whole G1). This hypothesis is also supported by the statistically significant predominance of B tympanograms in atopic children $(79.07 \%)$ with respect to non-atopics (56\%) $\left(\chi^{2}=4.053, P=0.044, \mathrm{OR}=2.97\right)$. Besides, our study shows that atopy may contribute to the severity of hearing loss; the mean air conduction pure tone was, respectively, $31.97 \mathrm{~dB}$ for atopics and $29.8 \mathrm{~dB}$ for non-atopics (index

Table 2 Distribution of OME suffered according to atopy, sex and audiological characteristics

\begin{tabular}{|c|c|c|c|c|}
\hline \multirow[t]{3}{*}{ Factors } & \multicolumn{4}{|c|}{ OME populations } \\
\hline & \multicolumn{2}{|c|}{ Atopics G1 } & \multicolumn{2}{|c|}{ Non-atopics G2 } \\
\hline & $N$ & $(\%)$ & $N$ & $(\%)$ \\
\hline \multicolumn{5}{|l|}{ Children } \\
\hline Boys & 7 & (29.16) & 5 & $(31.25)$ \\
\hline Girls & 17 & $(70.83)$ & 11 & $(68.75)$ \\
\hline \multicolumn{5}{|l|}{ OME } \\
\hline Unilateral & 5 & $(20.83)$ & 7 & $(43.75)$ \\
\hline Bilateral & 19 & (79.17) & 9 & $(56.25)$ \\
\hline \multicolumn{5}{|l|}{ Ears } \\
\hline Right & 22 & $(51.16)$ & 13 & $(52)$ \\
\hline Left & 21 & $(48.84)$ & 12 & $(48)$ \\
\hline \multicolumn{5}{|c|}{ Tympanogram } \\
\hline Tymp. C & 9 & (20.93) & 11 & (44) \\
\hline Tymp. B & 34 & (79.07) & 14 & $(56)$ \\
\hline \multicolumn{5}{|c|}{ Hearing threshold } \\
\hline $25-30 \mathrm{~dB}$ & 26 & $(60.46)$ & 16 & (64) \\
\hline $35-40 \mathrm{~dB}$ & 14 & $(32.56)$ & 8 & $(32)$ \\
\hline $45-50 \mathrm{~dB}$ & 2 & $(4.65)$ & 1 & (4) \\
\hline $55-60 \mathrm{~dB}$ & 1 & $(2.33)$ & & \\
\hline
\end{tabular}


correlation $r=0.99 ; P<0.0001)$. In particular in four ears, three of which belong to G1, a moderate hearing loss was evidenced. It was related to the contemporary presence of atelectasis that could be facilitated by chronic allergic reaction of the upper airway (Table 2).

In sum, we concluded that the point prevalence rate of OME among primary school children aged 5-6 years, in our series, was $12.9 \%$. The results clearly identify a group of variables as risk factors for OME. In particular, the present study showed that age and allergy may be important risk factors for OME. Of children with OME, $60 \%$ were atopic, whereas $42.85 \%$ of children with allergy were found to suffer from OME. These results, also based on the audiological measurements, seem to support the hypothesis that allergic inflammation could have a role in the genesis and recurrence of OME indirectly by causing a persistent blockage of the eustachian tube or directly by means of middle ear mucosa inflammation, but need further investigation with other studies.

Conflict of interest statement The authors report no conflict of interest. The authors alone are responsible for the content and writing of the paper.

\section{References}

1. Pelikan Z (2006) Chronic otitis media (secretory) and nasal allergy. Scr Med (BRNO) 79(4):177-198

2. Williamson I (2002) Otitis media with effusion. Clin Evid 7:469476

3. Takata GS, Chan LS, Morphew T, Mangione-Smith R, Morton SC, Shekelle P (2003) Evidence assessment of the accuracy of methods of diagnosing middle ear effusion in children with otitis media with effusion. Pediatrics 112:1379-1387

4. Kubba H, Pearson JP, Birchall JP (2000) The etiology of otitis media with effusion: a review. Clin Otolaryngol Allied Sci 25(3):181-194

5. Saim A, Saim L, Saim S, Ruszymah BHI, Sani A (1997) Prevalence of otitis media with effusion amongst pre-school children in Malaysia. Int J Pediatr Otorhinolaryngol 41:21-28

6. Caylan R, Bektas D, Atalay C, Korkmaz O (2006) Prevalence and risk factors of otitis media with effusion in Trabzon, a city in northeastern Turkey, with an emphasis on the recommendation of OME screening. Eur Arch Otorhinolaryngol 263:404-408

7. Paradise JL, Rockette HE, Colborn DK, Bernard BS, Smith CG, Kurs-Lasky M, Janosky JE (1997) Otitis media in 2253 Pittsburgh-area infants: prevalence and risk factors during the first two years of life. Pediatrics 99(3):318-333

8. Casselbrant ML, Mandel EM (2003) Epidemiology. In: Rosenfeld RM, Bluestone CD (eds) Evidence-based otitis media, 2nd edn. BC Decker, Hamilton, ON, pp 147-162

9. De Ru JA, Grote JJ (2004) Otitis media with effusion: disease or defense? A review of the literature. Int J Pediatr Otorhinolaryngol 68:331-339

10. Ryding M, White P, Kalm O (2004) Eustachian tube function and tympanic membrane findings after chronic secretory otitis media. Int J Pediatr Otorhinolaryngol 68(2):197-204
11. Fireman $P$ (1997) Otitis media and eustachian tube dysfunction: connection to allergic rhinitis. J Allergy Clin Immunol 99(2):S787-S797

12. Skoner PD (2000) Complication of allergic rhinitis. J Allergy Clin Immunol 105:605-609

13. Hurst DS, Amin K, Seveus L, Venge P (1999) Mast cells and tryptase in the middle ear of children with otitis media with effusion. Int J Pediatr Otorhinolaryngol 49:315-319

14. Umapathy D, Alles R, Scadding GK (2007) A community based questionnaire on the association between symptoms suggestive of otitis media with effusion, rhinitis and asthma in primary school children. Int J Pediatr Otorhinolaryngol 71:705-712

15. Bernstein JM (1993) The role of IgE-mediated hypersensitivity in the development of otitis media with effusion: a review. Otolaryngol Head Neck Surg 109:611-620

16. Tewfik TL, Mazer B (2006) The links between allergy and otitis media with effusion. Curr Opin Otolaryngol Head Neck Surg 14:187-190

17. Okur E, Yildirim I, Kilic MA, Guzelsoy S (2004) Prevalence of otitis media with effusion among primary school children in Kahramanmaras, in Turkey. Int $\mathrm{J}$ Pediatr Otorhinolaryngol 68(5):557-562

18. Martines F, Bentivegna D, Di Piazza F, Martinciglio G, Sciacca V, Martines E (2010) The point prevalence of otitis media with effusion among primary school children in Western children. Eur Arch Otorhinolaryngol 267(5):709-714

19. Schilder G, Zielhuis GA, Van Den Broek P (1993) The otological profile of a cohort of Dutch 7.5-8-year-olds. Clin Otolaryngol 18(1):48-54

20. El-Sayed Y, Zakzouk S (1995) Point prevalence of type B tympanogram in Riyadh. Int J Pediatr Otorhinolaryngol 31(1):53-61

21. Apostolopoulos K, Xenelis J, Tzagaroulakis A, Kandiloros D, Yiotakis J, Papafragou K (1998) The point prevalence of otitis media with effusion among school children in Greece. Int J Pediatr Otorhinolaryngol 44(3):207-214

22. Zielhuis GA, Rach GH, Den Bosch V, Den Broek V (1990) The prevalence of otitis media with effusion: a critical review of the literature. Clin Otolaryngol 15:283-288

23. Marseglia GL, Pagella F, Caimmi D, Caimmi S, Castellazzi AM, Poddighe D, Klersy C, Ciprandi G (2008) Increased risk of otitis media with effusion in allergic children presenting with adenoiditis. Otolaryngol Head Neck Surg 138:572-575

24. Fireman P (2000) Therapeutic approaches to allergic rhinitis: treating the child. J Allergy Clin Immunol 105:616-621

25. Nguyen LHP, Manoukian JJ, Sobol SE, Tewfik TL, Mazer BD, Schloss MD, Taha R, Hamid QA (2004) Similar allergic inflammation in the middle ear and the upper airway: evidence linking otitis media with effusion to the united airways concept. J Allergy Clin Immunol 114:1110-1115

26. Tomonaga K, Kurono Y, Moge G (1988) The role of nasal allergy in otitis media with effusion, a clinical study. Acta Otolaryngol 458:41-47

27. Nsouli TM, Nsouli SM, Linde RE, Scanlon RT, Bellanti JA (1994) The role of food allergy in serous otitis media. Ann Allergy 73(3):215-219

28. Hurst DS, Venge P (2000) Evidence of eosinophil, neutrophil, and mast-cell mediators in the effusion of OME patients with and without atopy. Allergy 55:435-441

29. McMahan JT, Calenoff E, Croft DJ, Barenholtz L, Weber LD (1981) Chronic otitis media with effusion and allergy: modified RAST analysis of 119 cases. Otolaryngol Head Neck Surg 89:427-431

30. Hall LJ, Lukat RM (1981) Results of allergy treatment on the eustachian tube in chronic serous otitis media. Am J Otol 3:116-121 